Veer, A. de, Francke, A., Poortvliet, E.P.

Nurses' involvement in end-of-life decisions.

Cancer Nursing: 2008, 33(3), 222-228

\begin{tabular}{|l|l|}
\hline Postprint Version & 1.0 \\
\hline Journal website & $\begin{array}{l}\text { http://pt.wkhealth.com/pt/re/lwwgateway/landingpage.htm;jsessionid=LtqXLh } \\
\text { MNhhLC02v7QW6b1bhd0rKzLh16ShdXdnTWJycnlr3qJyJq!- }\end{array}$ \\
\hline Pubmed link & $\begin{array}{l}\text { 2121125135!181195628!8091!-1?an=00002820-200805000-00010 } \\
\text { http://www.ncbi.nlm.nih.gov/pubmed/18453879?ordinalpos=1\&itool=EntrezSy } \\
\text { stem2.PEntrez.Pubmed.Pubmed ResultsPanel.Pubmed RVDocSum }\end{array}$ \\
\hline DOI & $\underline{2}$ \\
\hline
\end{tabular}

This is a NIVEL certified Post Print, more info at http://www.nivel.eu

\title{
Nurses' Involvement in End-of-life Decisions
}

\author{
DE Veer, Anke J.E. PhD; Francke, Anneke L. PhD, RN; PoOrtVliet, ERnst-PAul \\ MSC, RN
}

Authors' Affiliations: Netherlands Institute of Health Services Research (NIVEL) (Drs de Veer and Francke); and Netherlands Centre for Excellence in Nursing (LEVV), Utrecht, The Netherlands (Mr Poortvliet).

Corresponding author: Anke J.E. de Veer, PhD, Netherlands Institute of Health Services

Research (NIVEL), PO Box 1568, 3500 BN, Utrecht, The Netherlands (a.deveer@nivel.nl).

\begin{abstract}
In Dutch healthcare, patients and physicians are responsible for medical endof-life decisions. These include nontreatment decisions, withholding or withdrawing parenteral hydration and nutrition where the patient can no longer drink or eat, relieving pain and other symptoms with drugs that might shorten life, euthanasia, and physician-assisted suicide. The objective of this study is to investigate the views of nurses on their role with regard to discussing these kinds of decisions, as well as their actual role in the decision-making process. Nurses $(n=489)$ involved in palliative terminal care answered questions about their preferred and actual role in end-of-life decision-making processes. Nurses want to be involved in making end-of-life decisions, but this depends partly on the kind of decision that has to be taken. When caring for terminal patients, $62 \%$ of the nurses usually talk about such decisions with patients or their families. Three-quarters of the nurses had been involved in an end-of-life decisionmaking process in the previous 2 years, mostly by talking with the physician and the patient's family. It is concluded that physicians should discuss these decisions with nurses more often. The finding that characteristics of the nurses influence their role in end-of-life decision-making processes emphasizes the importance of developing mechanisms to ensure that end-of-life decisions are made in a consistent manner and do not depend on the demographic characteristics of nurses.
\end{abstract}

In the Netherlands, as in many other Western countries, physicians and patients are responsible for making medical end-of-life decisions and carrying them out. This article reports on the role of nurses with regard to discussing medical end-of-life decisions such as nontreatment, withholding or withdrawing parenteral hydration and nutrition, relieving pain 
and other symptoms with drugs that might shorten life, euthanasia, and physician-assisted suicide.

Medical end-of-life decisions are often made in the final phase of life. In a study 1 on the frequency and characteristics of end-of-life decision-making practices in 6 European countries (Belgium, Denmark, Italy, the Netherlands, Sweden, and Switzerland), the proportion of deaths preceded by any end-of-life decision ranged from 23\% (Italy) to $51 \%$ (Switzerland). In the Netherlands, the estimated proportion was 44\%. After the 1990 to 2001 period, the proportion of deaths preceded by any end-of-life decision in the Netherlands increased slightly from 39\% to 44\%르 and stabilized from 2001 onwards (43\% in 2005). 3 In some cases, when palliative options have been exhausted and there is unbearable and hopeless suffering, active termination of a life may be discussed. Except for euthanasia, there is no legislation on medical end-of-life decisions and the role of professionals in Europe.4 The only European countries that have legislation on euthanasia are the Netherlands, Belgium, and Switzerland. In the Netherlands, euthanasia is understood to mean the termination of life by a physician, under strict conditions, at the request of a patient. $\underline{5}$ In recent decades, requirements of due care have been formulated through jurisprudence, and these have been incorporated in the euthanasia legislation, which came into force in the Netherlands on April 1, 2002. This legislation cements the requirements and review procedures that had previously been used in medical and legal practice. The Dutch Penal Code stipulates that a physician who performs euthanasia is liable to prosecution unless the physician has complied with the requirements of due care required by law and has reported the nonnatural death to a "regional euthanasia review committee." The requirements of due care mean that the physician 3,5:

* must be convinced that there is a voluntary and carefully considered request from the patient;

* must be convinced that the patient's suffering is hopeless and unbearable;

* has to tell the patient about his or her situation and prospects;

* has to consult at least one other independent physician who sees the patient and gives his or her opinion in writing about the due care as referred to in the first 3 requirements above;

* has to become convinced, together with the patient, that there is no other reasonable solution for the situation that the patient is in. This last requirement of due care means that it has to be ascertained whether there are further possibilities in the area of palliative care to reduce the suffering; and

* has to implement the termination of life or assisted suicide with due medical care.

Euthanasia was recorded in 2.6\% of all deaths in 2001 in the Netherlands; this was more frequent than in Belgium, Denmark, Italy, Sweden, or Switzerland. 1 The number of requests for euthanasia, however, decreased to $1.7 \%$ in 2005.3 The reasons for requests for euthanasia have also changed. 6 The importance of pain in such requests decreased significantly, parallel to a proportional increase in the importance of deteriorating health. However, most medical end-of-life decisions do not concern euthanasia but involve the cessation of treatment and the alleviation of pain and symptoms with possible life-shortening effects ( $40 \%$ of all deaths in 2001).1

Relevant studies on the decision-making process in cases of medical end-of-life decisions often concentrate on the role of physicians.7 This is not surprising because these decisions are the responsibility of the physician attending the patient. However, it can be assumed that nurses also play a role in this process because the nature of their work involves them directly in the care of terminally ill patients.8,9 Nurses' observations of the needs of patients and their communication with patients may play a valuable role in decision making.

The aforementioned European study on end-of-life decisions 1 shows that physicians in Belgium (57\%) and Switzerland (50\%) more often discuss the medical end-of-life care with the nursing staff than in the other countries. In the Netherlands, $36 \%$ of the end-of-life decisions were discussed with the nursing staff. Studies suggest that the involvement 
depends on the beliefs and demographic characteristics of nurses (eg, religion, educational background, age).10-13

The measured involvement of nurses also depends on the person reporting the involvement. Nurses are found to have different perceptions of their involvement. In a study in French intensive care units, for instance, only $27 \%$ of nursing staff members and $50 \%$ of physicians believed that the nursing staff was actually involved in decision making.14

Finally, the role of nurses may also vary among healthcare sectors, that is, the duration of the relationship between the patient and the nurse and whether nurses and physicians work in the same organization. In homecare settings, district nurses and general practitioners usually work separately and do not often see one another. Research shows that district nurses were involved in the decision-making process in fewer cases than were nurses in institutional settings.7,13 It is also not unusual for the patients in the homecare sector to have made known the wish to discuss an end-of-life decision before their first contact with a district nurse. 7 In institutions for mentally handicapped people and psychiatric care, nurses often have a longer-lasting and closer relationship with patients. In a study of institutions for mentally handicapped people, the physicians discussed the decision with the nursing staff in $90 \%$ of the deaths in which an end-of-life decision was made.15

The objective of this study is to investigate the views of nurses on their role in discussing end-of-life decisions and their actual role in the decision-making process and how this relates to the background characteristics of nurses.

\section{RESEARCH QUESTIONS}

With regard to the study objective, the following questions will be answered:

1. How do nurses view their role in the following medical end-of-life decisions: nontreatment decisions, withholding or withdrawing parenteral hydration and nutrition, relieving pain and symptoms with drugs that might shorten life, euthanasia, and physicianassisted suicide?

2. What role do nurses actually have in these medical end-of-life decisions?

3. What is the relationship between nurses' views and their actual involvement and sociodemographic data (type of healthcare setting, years of work experience, number of working hours per week, number of palliative terminal patients, sex, and education level)?

\section{METHODS}

\section{Participants}

The study population was made up of nurses from a nationally representative nursing panel. The panel consists of a permanent group of nurses who are prepared to fill in a postal questionnaire at least twice a year. The education background of these nurses ranged from at least 4 years of basic professional training (bachelor of science in nursing) to 2 or 3 years of professional training (associate degree in nursing). Candidates for the nursing panel were recruited from a random sample of nurses registered with the National Social Insurance Services Company, where all employees are required to be insured.

In 2002, a total of 734 nurses filled in a postal questionnaire about end-of-life care. Some nurses work in settings where patients do not usually die. For this article, we included only nurses who had given palliative terminal care to at least 1 patient in the previous 2 years, wherein patients died after a spell of sickness resulting from a chronic physical illness or old age. In these cases, there were probably opportunities to talk about end-of-life decisions. This selection resulted in 489 nurses (67\% of the total response group). Table 1 shows the characteristics of these respondents. 


\section{[TABLE 1]}

\section{Questionnaire}

The questionnaire contained questions concerning the nurses' preferred involvement in endof-life decisions as well as their actual involvement. Preferred involvement refers to whether the nurse wants to be consulted by the physician in making end-of-life decisions. Actual involvement refers to participation in the decision-making process, specifically, whether nurses discuss requests for end-of-life decisions with either the physician, the patient, or the family.

\section{PREFERRED INVOLVEMENT IN END-OF-LIFE DECISIONS (5 ITEMS, 5-POINT SCALE, CRONBACH [alpha] =.91).}

Five kinds of decision that might hasten death or deliberately cause death were described. These were withholding or withdrawing life-prolonging treatments (nontreatment decision), withholding or withdrawing parenteral hydration and nutrition where the patient could no longer eat or drink, relieving pain and other symptoms with opiates or similar drugs that might shorten life, euthanasia (ending life by the physician giving lethal drugs), and physician-assisted suicide (ending life by the patient with lethal drugs provided by the physician). For each situation, a statement was formulated, to the effect that: "the physician should involve me (the nurse) in this decision (description of the decision) if I am providing care to the patient." The nurse was asked whether he or she (strongly) agreed, was neutral, or (strongly) disagreed with the statement.

\section{ACTUAL INVOLVEMENT}

The actual involvement was measured in 2 ways: (a) the tendency of the nurse to talk about end-of-life decisions when giving regular care to a palliative terminal patient (ie, irrespective of whether such a decision must actually be made) and (b) the involvement in the end-of-life decision-making process if such decisions are to be taken by the physician and the patient.

A. Tendency to talk about end-of-life decisions with the patient or family ( 2 items, yes or no). Nurses were asked whether they had talked about end-of-life decisions with most of the palliative terminal patients they had cared for during the previous 2 years (yes or no). We also asked whether they talked about such decisions with the family (eg, spouse, child) in most of these cases (yes or no). If the nurse answered yes to at least 1 question, the tendency to talk about end-of-life decisions was scored as yes (1). If both answers were no, the score was no (0).

B. Involvement in end-of-life decision-making process (20 items, yes or no). Four questions were asked on each of the 5 previously mentioned decisions. The first question concerned involvement in this type of decision during the previous 2 years (yes or no) and the number of patients concerned. If the nurse had been involved in the decision-making process, the nurse indicated with whom he or she (usually) had been talking: ( $a$ ) the patient, $(b)$ the family, and (c) the physician (yes or no).

The questions were formulated by the researchers. Sixteen experts in the field of terminal care individually assessed a draft questionnaire. They were asked to comment on the content validity of the questionnaire (eg, regarding the described end-of-life decisions) and to judge whether the questions and possible answers were unequivocal. Eight experts were nurses with practical experience, often working in centers for cancer and palliative care. Eight were researchers in the field of end-of-life decisions at universities in the Netherlands and Belgium.

\section{Analyses}

Categorical variables were summarized by using proportions. Continuous variables were summarized by using means and standard deviations. To investigate the relationship between background characteristics and the preferred involvement and actual involvement in end-of- 
life decisions, univariate analyses of variance were used. In these analyses, the categorical background characteristics (healthcare sector, education level, and sex) were treated as factors. Continuous background characteristics (working experience, number of working hours per week, and number of palliative terminal patients) were covariates.

Because the tendency to talk with the patient and/or family about end-of-life decisions is a dichotomous variable, we chose to conduct a logistic regression analysis to investigate determinants of this tendency $(1=$ in most cases talks with patient or family about end-of-life decisions, $0=$ in less than half of the cases talks with patient or family about end-of-life decisions). All coefficients were tested for significance at a 2-tailed $P<.05$ level, and nonstandardized $B$ s are mentioned. The sign of $B$ reflects a positive or negative relationship between the independent and dependent variable. For the categorical independent variables with more than 2 categories, we chose the category nearest to the overall mean as the reference group.

\section{RESULTS}

\section{Preferred Involvement in End-of-life Decisions}

In general, nurses preferred to be involved by the physician in end-of-life decisions, depending on the kind of decision that had to be taken (Table 2). Most nurses (77\%-82\%) preferred to discuss such medical decisions in the final phase of life that might hasten death (eg, whether to stop life-prolonging treatments). A smaller number preferred to be involved in decisions on deliberately causing death (euthanasia or physician-assisted suicide).

\section{[TABLE 2]}

\section{The Role of Nurses in the End-of-life Decision-Making Process}

The actual role of nurses in the decision-making process is measured by the tendency to talk about end-of-life decisions with patients or their families and by the number of end-oflife decision-making processes they had been involved in during the previous 2 years. When caring for a patient in the final phase of life, 38\% of the nurses will (usually) not talk about issues related to end-of-life decisions (Table 3). That means that $62 \%$ generally do talk about this issue, most often with the patient and the family.

\section{[TABLE 3]}

Table 4 shows that three-quarters (76\%) of the nurses with palliative terminal patients have been involved in a medical end-of-life decision-making process in the previous 2 years. The nurses were involved in an average of 8 cases in a 2-year period. Most often, the decision related to the use of opiates or similar drugs for pain and symptom relief that may possibly hasten death. Nineteen percent of the nurses played a role in a decision as to whether to carry out euthanasia. Involvements in decisions on active ending of life by physician-assisted suicide were scarce (6 nurses, or $1 \%$ ).

\section{[TABLE 4]}

If the nurse had played a role in a decision, the nurse indicated with whom he or she had discussed it. Most nurses talked with the family (Table 5). Where euthanasia is concerned, $83 \%$ discussed the situation with the family. In cases of other end-of-life decisions, the percentages were even higher.

[TABLE 5]

Most nurses also discussed end-of-life decisions with the physician. The extent to which nurses spoke with the patients depended on the kind of decision that was being discussed. In 
the case of euthanasia, most nurses (87\%) (also) talked with the patient. However, when stopping parenteral hydration and nutrition was being considered, half (49\%) of the nurses did not discuss it with the patients.

\section{Background Characteristics}

Before analyzing the relationship between preferred involvement, tendency to talk about end-of-life decisions, and actual involvement on the one hand and background characteristics on the other hand, we investigated the interrelations between the 3 dependent variables. All variables were interrelated. The wish to get involved in the physicians' decision-making process related to the tendency to talk about end-of-life decisions during the care process ( $F$ $=27.01, P<.001$ ) as well as with the actual involvement in such decisions (Pearson correlation coefficient $=0.241, P<.001$ ). Nurses who tend to talk about end-of-life decisions when giving care are twice as frequently engaged in decision-making processes (mean number of decisions $=10.5$ vs $4.6 ; F=23.57, P<.001$ ).

The preferred involvement in the end-of-life decision-making process was found to be related to the healthcare sector, education level, and the number of weekly working hours (Table 6). Nurses in psychiatry, in particular, preferred to become involved, whereas fewer nurses in homes for elderly people did. Nurses with a high or intermediate education level and nurses working more hours per week preferred to become involved more frequently. No associations were found with the other background characteristics (sex, working experience, and number of palliative terminal patients).

\section{[TABLE 6]}

Nurses working in nursing homes tended to talk more about end-of-life decisions when caring for a patient, whereas nurses in psychiatry tended to talk less about it (Table 6). Nurses with more working experience, working more hours per week, and with many palliative terminal patients talked more frequently with the patients or their families about medical end-of-life decisions. No relationship was found with sex and education level.

Not surprisingly, involvement in the decision-making process is strongly positively related to the number of palliative terminal patients of the nurse (Table 6). In addition, nurses who are frequently engaged in an end-of-life decision-making process more often work in hospitals and nursing homes, work more hours per week, and are more frequently male.

\section{DISCUSSION}

This study highlights the role of nurses in end-of-life decisions, seen from the viewpoint of nurses. Most nurses prefer to be brought into end-of-life decisions by the physician, but this depends, in part, on the kind of decision that has to be taken. When euthanasia or physicianassisted suicide is discussed, a larger number of nurses do not want to be involved in the decision-making process than when nonactive end-of-life decisions (eg, stopping lifeprolonging treatment) are discussed. This study shows not only that most nurses prefer to be involved in end-of-life decisions but also that many of them do talk about such decisions with the patient and/or the family in daily practice.

A remarkable finding is that nurses more often tend to talk about end-of-life decisions with the family (57\%) than with the patient (45\%) in the final phase of the care. In the actual decision-making process, the nurse also talks with the family more often. It may be easier for nurses to talk about these issues with relatives of the patient than with the patient. Another explanation is that the formal decision-making process, especially in cases of stopping hydration and nutrition and, to a lesser extent, in cases of possible life-shortening pain and symptom relief and nontreatment decisions, takes place in a later phase of life, when communication with the patient is difficult or indeed no longer possible (eg, coma or dementia). 
In nursing homes and hospitals, nurses are more frequently engaged by physicians in the decision-making process. This may be because of the fact that nurses and physicians work in the same building (in the Netherlands, all nursing homes have their own physician), which makes it easier for them to consult one another. Another explanation is that death is more common in nursing homes and hospitals, which might lead to more openness about end-oflife decisions in these sectors than in other sectors.16

Nurses working in psychiatry prefer to be involved by the physician in end-of-life decisions more frequently than do nurses in other healthcare sectors. When they give care to a palliative terminal patient, however, they tend to talk less about end-of-life decisions. This discrepancy may be because of the fact that nurses in psychiatry do not have many of these patients. They probably do not have sufficient "tools" for the discussion of end-of-life issues and need further training.

Clearly, most nurses (prefer to) talk about medical end-of-life decisions. The results show that further discussion about the role of nurses in end-of-life decisions is necessary. Nurses are directly involved with terminally ill patients and prefer to be involved by the physician in end-of-life decisions. Their central role in the care allows nurses to make a valuable contribution to the discussion on end-of-life decision making. Other research shows that nurses are mostly well informed about their patients' situation and preferences regarding end of life 17 and that nurses and physicians have the same moral commitment to a patient and experience the same ethical problems.18 When nurses and physicians share these problems, the burden of this care may also become less heavy. In a study on decisions about parenteral hydration and nutrition in nursing homes, nurses were an important source of information for nursing home physicians in gaining an impression of the condition of the patient during the day.19 Nurses also played a central role in initiating the decision-making process by observing changes in the patients' condition and reporting these changes to the physician.

Other research, however, shows that in most deaths (64\%) preceded by an end-of-life decision, the physician did not discuss this decision with a nurse.2 Research also shows that nurses in Belgium were largely involved in administering lethal drugs in end-of-life decisions, whereas their participation in the decision-making process was limited.20 The practical implications of this study may be 3-fold. First, because nurses prefer to be involved by physicians in the end-of-life decision-making process, and this apparently is not always the case, physicians should discuss these decisions with nurses more often. If the nurses' preference to be involved is taken into account, it probably becomes easier for nurses to carry out patient care that results from the patients' own wishes.

Second, whenever nurses do play a role in the decision-making process, increased clarity about their role is needed. The difference between nurses and physicians is that physicians are legally responsible for making decisions.5,21 A more explicit description of the role of nurses is necessary. Therefore, in 2006, the respective associations of physicians and nurses jointly published guidelines describing the roles of physicians and nurses in the different phases of the care process concerning euthanasia.22 By implementing these guidelines, there will be more clarity about the position and the care of nurses in end-of-life decisions.

Third, we found that the role of nurses is related to background characteristics. The finding that the characteristics of professionals may influence their role in end-of-life decisionmaking processes has been reported previously.23-25 A review study on written institutional policies on end-of-life decisions shows that written documents primarily provide technical and procedural guidelines and give little attention to the specific roles of involved parties.26 Such findings emphasize the importance of institutes developing procedures to ensure that medical end-of-life decisions are made in a consistent manner and do not depend on the demographic characteristics of the nurses. 


\begin{tabular}{|c|c|c|}
\hline & $\mathrm{n}$ & $\%$ \\
\hline \multicolumn{3}{|l|}{ Healthcare sector } \\
\hline Hospitals & 66 & 13.5 \\
\hline Psychiatry & 33 & 6.7 \\
\hline $\begin{array}{l}\text { Organizations for } \\
\text { the mentally handicapped }\end{array}$ & 44 & 9.0 \\
\hline Homecare & 177 & 36.2 \\
\hline Homes for the elderly & 85 & 17.4 \\
\hline Nursing homes & 84 & 17.2 \\
\hline \multicolumn{3}{|l|}{ Education level } \\
\hline High (at least 4 years) & 77 & 15.7 \\
\hline Intermediate (3-3.5 years) & 161 & 32.9 \\
\hline Low ( 2 or 3 years) & 251 & 51.3 \\
\hline \multicolumn{3}{|l|}{ Sex } \\
\hline Male & 32 & 6.5 \\
\hline Female & 456 & 93.3 \\
\hline \multirow[t]{2}{*}{ Missing } & 1 & 0.2 \\
\hline & Mean & SD (Range) \\
\hline Years of working experience & 15.2 & $7.9(0.5-37)$ \\
\hline $\begin{array}{l}\text { No. of working hours } \\
\text { per week }\end{array}$ & 23.1 & $8.5(3-40)$ \\
\hline $\begin{array}{l}\text { No. of palliative terminal } \\
\text { care patients in } 2 \text { years }\end{array}$ & 10.4 & $10.3(1-60)$ \\
\hline
\end{tabular}




\section{Table $2 \cdot$ Preferred Involvement in the End-of-} life Decision Process $(n=489)$

The physician should involve me if I am caring for a patient and a decision has to (Strongly)

(Strongly) be made about Agree, \% Neutral, \% Disagree, \%

\begin{tabular}{|c|c|c|c|}
\hline $\begin{array}{l}\text { parenteral hydration } \\
\text { and nutrition. }\end{array}$ & 82 & 10 & 8 \\
\hline $\begin{array}{l}\text { pain and symptom } \\
\text { relief. }\end{array}$ & 79 & 13 & 8 \\
\hline $\begin{array}{l}\text { nontreatment } \\
\text { decisions. }\end{array}$ & 77 & 14 & 9 \\
\hline euthanasia. & 61 & 22 & 17 \\
\hline $\begin{array}{l}\text { physician-assisted } \\
\text { suicide. }\end{array}$ & 49 & 30 & 21 \\
\hline \multicolumn{4}{|c|}{$\begin{aligned} 1 . & \text { Table } 3 \\
& \text { Tendency to Talk About End-of-lit } \\
& \text { Decisions With the Patient or the } \\
& \text { Family }(n=489)\end{aligned}$} \\
\hline
\end{tabular}

With the majority of my palliative terminal patients, I...

do not talk about end-of-life decisions.

talk with the patient as well as the family about $40 \%$ end-of-life decisions. talk with the family about end-of-life decisions. $17 \%$ talk with the patient about end-of-life decisions. 


\begin{tabular}{|c|c|c|c|}
\hline \multicolumn{4}{|c|}{$\begin{array}{l}\text { 1.: Table } 4 \cdot \text { Actual Involvement in End-of-life } \\
\text { Decisions in the Previous } 2 \text { Years } \\
(n=489)\end{array}$} \\
\hline Kind of Decision ${ }^{a}$ & $\begin{array}{l}\text { Percentage } \\
\text { of Nurses } \\
\text { Involved }\end{array}$ & $\begin{array}{l}\text { No. of } \\
\text { Cases } \\
\text { (Mean) }\end{array}$ & $\begin{array}{l}\text { Variation } \\
\text { in No. of } \\
\text { Cases (SD) }\end{array}$ \\
\hline $\begin{array}{l}\text { Parenteral hydration } \\
\text { and nutrition }\end{array}$ & 50 & 2.1 & 4.7 \\
\hline Pain and symptom relief & 63 & 3.4 & 6.0 \\
\hline Nontreatment decisions & 46 & 2.3 & 5.2 \\
\hline Euthanasia & 19 & 0.4 & 1.4 \\
\hline Physician-assisted suicide & 1 & 0.03 & 0.3 \\
\hline $\begin{array}{l}\text { Overall (irrespective of } \\
\text { kind of decision) }\end{array}$ & 76 & 8.3 & 13.2 \\
\hline \multicolumn{4}{|c|}{${ }^{a}$ Nurses could have been involved in several kinds of end-of-life decisions. } \\
\hline \multicolumn{4}{|c|}{$\begin{array}{c}\hat{H}^{*} \text { Table } 5 \text { - Person the Nurses Were Speaking } \\
\text { With in the End-of-life Decision- } \\
\text { Making Process }\end{array}$} \\
\hline Kind of Decision $^{a}$ & Patient & Family & Physician \\
\hline $\begin{array}{l}\text { Parenteral hydration and } \\
\text { nutrition }(\mathrm{n}=245)\end{array}$ & $49 \%$ & $91 \%$ & $84 \%$ \\
\hline $\begin{array}{l}\text { Pain and symptom relief } \\
\qquad(\mathrm{n}=308)\end{array}$ & $61 \%$ & $91 \%$ & $91 \%$ \\
\hline $\begin{array}{l}\text { Nontreatment decisions } \\
\qquad(\mathrm{n}=225)\end{array}$ & $67 \%$ & $85 \%$ & $80 \%$ \\
\hline Euthanasia $(\mathrm{n}=92)$ & $87 \%$ & $83 \%$ & $74 \%$ \\
\hline
\end{tabular}

${ }^{a}$ Because only 6 persons were involved in the decision-making process concerning physician-assisted suicide, this kind of decision was left out in the analysis. 


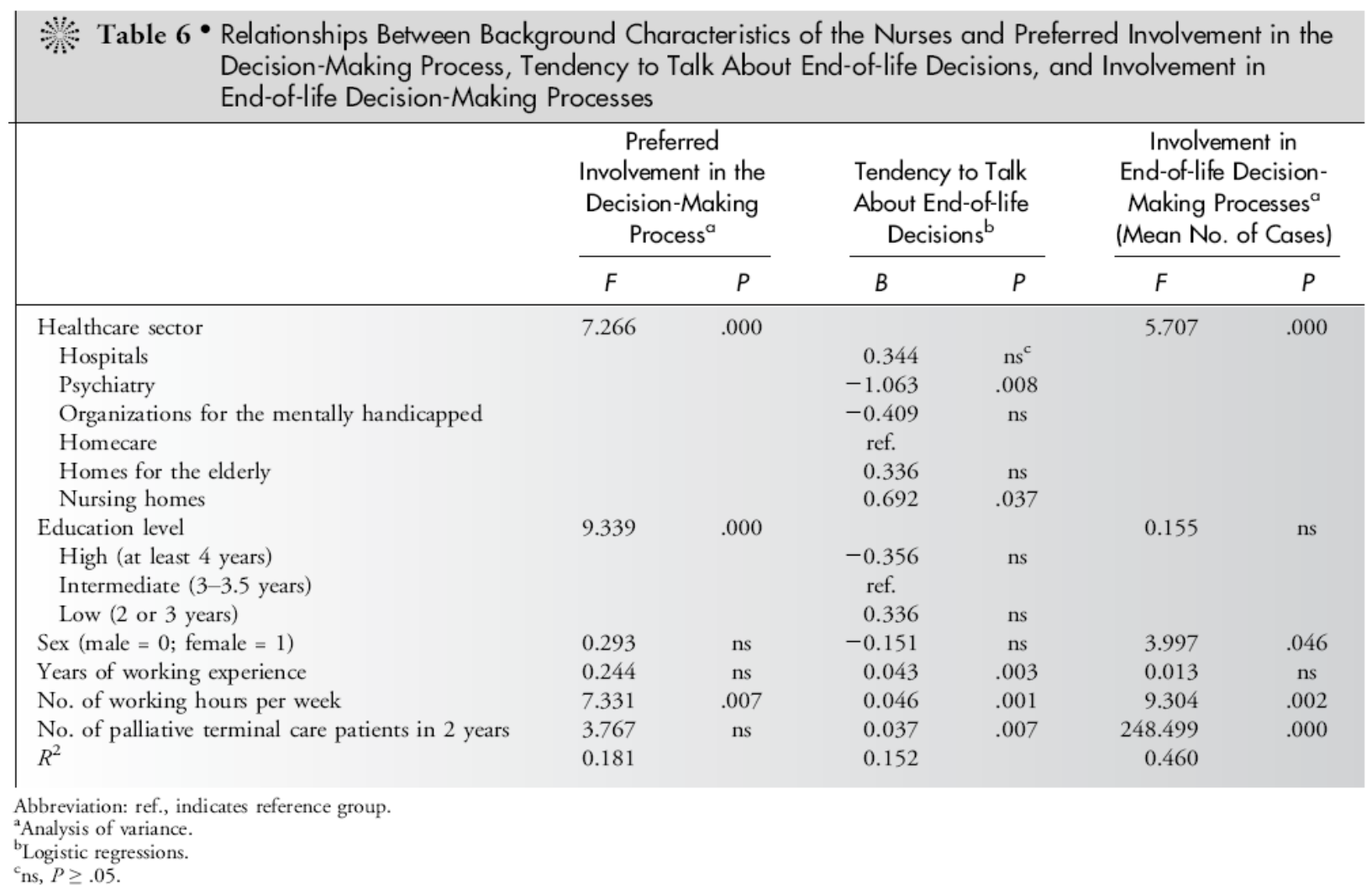

\section{REFERENCES}

1. Van der Heide A, Deliens L, Faisst K, et al. End-of-life decision-making in six European countries: descriptive study. Lancet. 2003;362(9381):345-350.

2. Onwuteaka-Philipsen BD, Van der Heide A, Koper D, et al. Euthanasia and other end-oflife decisions in the Netherlands in 1990, 1995, and 2001. Lancet. 2003;362(9381):395399.

3. Onwuteaka-Philipsen BD, Gevers JKM, Van der Heide A, et al. Evaluatie Wet toetsing levensbeëindiging op verzoek en hulp bij zelfdoding. [Report on the Evaluation of the Termination of Life on Request and Assisted Suicide Act]. Den Haag, The Netherlands: ZonMw; 2007.

4. Fasier T, Lautrette A, Ciroldi M, Azoulay E. Care at the end of life in critically ill patients: the European perspective. Curr Opin Crit Care. 2005;11:616-623.

5. Francke AL. Palliative Care for Terminally III Patients in the Netherlands. Dutch Government Policy. The Hague, The Netherlands: Ministry of Health, Welfare and Sports; 2003.

6. Marquet RL, Bartelds A, Visser GJ, Spreeuwenberg P, Peters L. Twenty five years of requests for euthanasia and physician assisted suicide in Dutch general practice: trend analysis. BMJ. 2003;327:201-202.

7. Van Bruchem-van de Scheur GG, Van der Arend JG, Spreeuwenberg C, Huijer Abu-Saad $\mathrm{H}$, Ter Meulen RHJ. Euthanasia and physician-assisted suicide in the Dutch homecare sector: the role of the district nurse. J Adv Nurs. 2007;58(1):44-52.

8. Van der Scheur G, Van der Arend A. The role of nurses in euthanasia: a Dutch study. Nurs Ethics. 1998;5:497-508.

9. Young MG, Ogden RD. The role of nurses in AIDS care regarding voluntary euthanasia and assisted suicide: a call for further dialogue. J Adv Nurs. 2000;31(3):513-519.

10. Benbenishty J, De Keyzer Ganz F, Lippert A, et al. Nurse involvement in end-of-life decision making: the ETHICUS Study. Intensive Care Med. 2006;32:129-132.

11. Verpoort C, Gastmans C, Dierckx de Casterlé B. Palliative care nurses' views on euthanasia. J Adv Nurs. 2004;47(6):592-600. 
12. Cohen J, Marcoux I, Bilsen J, Deboosere P, Van der Wal G, Deliens L. European public acceptance of euthanasia: socio-demographic and cultural factors associated with the acceptance of euthanasia in 33 European countries. Soc Sci Med. 2006;63:743-756. doi: 10.1016/J.socscimed.206.01.026.

13. Sprung CL, Carmel S, Sjokvist P, et al. Attitudes of European physicians, nurses, patients, and families regarding end-of-life decisions: the ETHICATT study. Intensive Care Med. 2007;33:104-110. doi: 10.1007/s00134-006-0405-1.

14. Ferrand E, Lemaire F, Regnier B, et al. Discrepancies between perceptions by physicians and nursing staff of intensive care unit end-of-life decision. Am J Respir Crit Care Med. 2003;167(10):1310-1315.

15. Van Thiel GJ, Van Delden JJ, De Haak K, Huibers AK. Retrospective study of doctors' "end of life decisions" in caring for mentally handicapped people in institutions in The Netherlands. BMJ. 1997;315:88-91.

16. De Gendt C, Bilsen J, Vander Sichele R, Van Den Noortgate N, Lambert M, Deliens L. Nurses' involvement in 'do not resuscitate' decisions on acute elder care wards. J Adv Nurs. 2007;57(4):404-409. doi: 10.1111/j.1365-2648.2006.04090.x.

17. Hildén HM, Louhiala P, Honkasalo ML, Palo J. Finnish nurses' views on end-of-life discussions and a comparison with physicians' views. Nurs Ethics. 2004;11(2):165-178. doi: 10.1191/0969733004ne681oa.

18. Oberle K, Hughes D. Doctors' and nurses' perceptions of ethical problems in end-of-life decisions. J Adv Nurs. 2001;33(6):707-715.

19. Pasman HRW, Onwuteaka-Philipsen BD, Van Wigcheren PT, Ooms ME, Ribbe MW, Van der Wal G. Al dan niet afzien van kunstmatige toediening van vocht en/of voedsel bij psychogeriatrische verpleeghuispatiënten. [Whether or Not to Discontinue Artificial Feeding and/or Hydration of Psycho-geriatric Nursing Home Patients] Besluit, klinisch beloop en kwaliteit van sterven. Amsterdam: VU Medisch Centrum; 2003

20. Bilsen JJR, Vander Stichele RH, Mortier F, Deliens L. Involvement of nurses in physician assisted dying. J Adv Nurs. 2004;47(6):583-591

21. Van der Scheur GG, Van der Arend AJG. Voorbereidende handelingen bij euthanasie en hulp bij zelfdoding: een taak voor verpleegkundigen? [Preparatory activities for euthanasia and assisted death: a task for nurses?] Verpleegkunde. 2003;18(2):123-125.

22. AVVV/Nu'91/KNMG. Handreiking voor Samenwerking Artsen, Verpleegkundigen en Verzorgenden bij Euthanasie. [Guidelines Concerning the Collaboration Between Doctors, Nurses and Carers With Regard to Euthanasia] Utrecht: AVVV/Nu'91/KNMG; 2006.

23. Cook DJ, Guyat GH, Jeaschke R, et al. Determinants in Canadian health care workers of the decision to withdraw life support from the critically ill. JAMA. 1995;273(9):703-708.

24. Dawe U, Verhoef MJ, Page SA. Treatment refusal: the beliefs and experiences of Alberta nurses. Int J Nurs Stud. 2002;39:71-77.

25. Rurup ML, Onwuteaka-Philipsen D, Pasman RW, Ribbe MW, Van der Wal G. Attitudes of physicians, nurses and relatives towards end-of-life decisions concerning nursing home patients with dementia. Patient Educ Couns. 2006;61:372-380.

26. Lemiengre J, de Casterlé BD, Van Craen K, Schotsmans P, Gastmans C. Institutional ethics policies on medical end-of-life decisions: a literature review. Health Policy. 2007;83(2-3):131-143. doi: 10.1016/j.healthpol.2007.02.013. 